شملت الدراسة 72 عينة دم مأخوذة من أشخاص أصحاء ،كان منها ( 30 ) عينة دم لأطفال

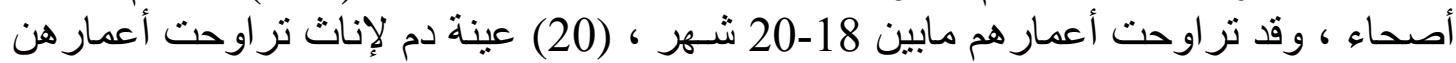

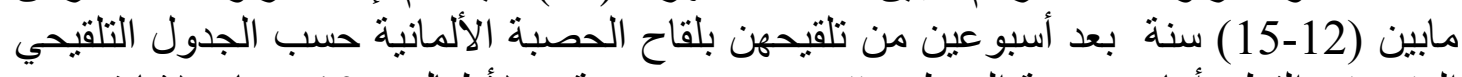

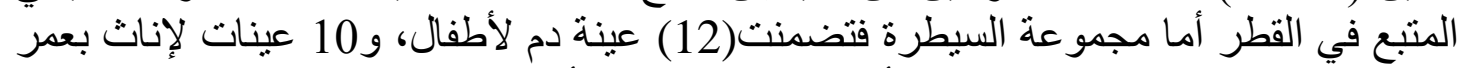

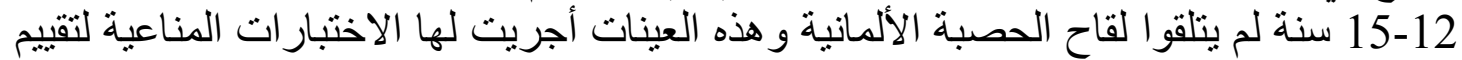

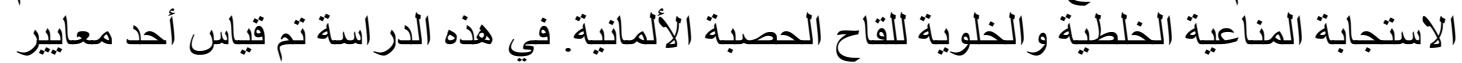

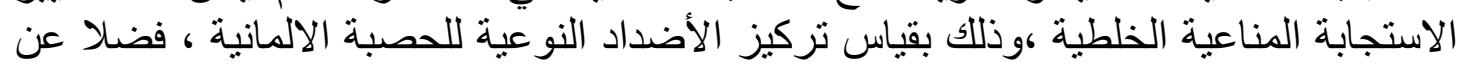

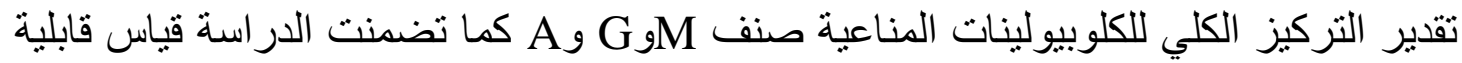

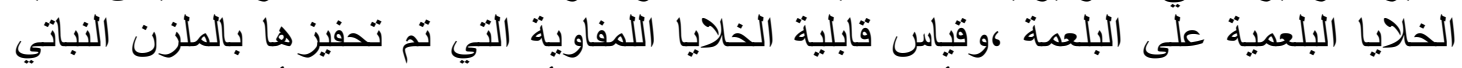

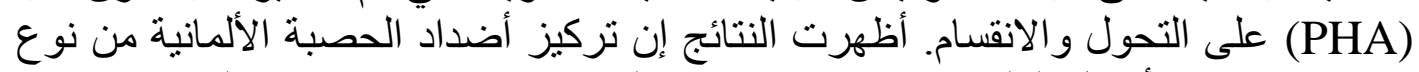

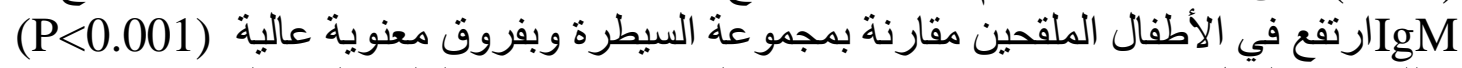

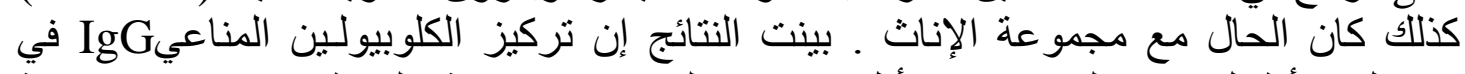

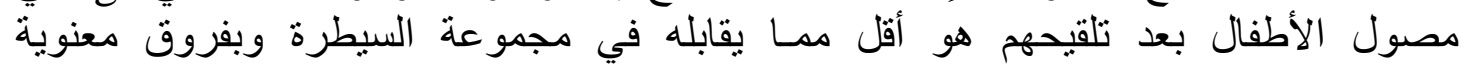

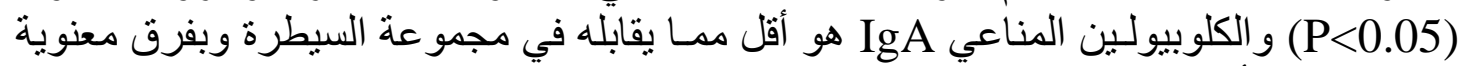

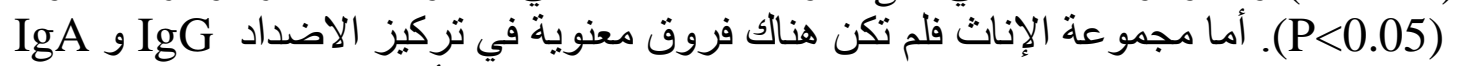

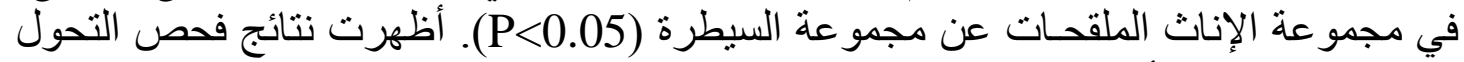

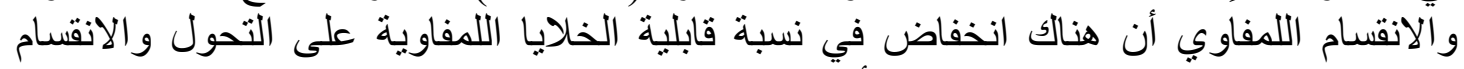

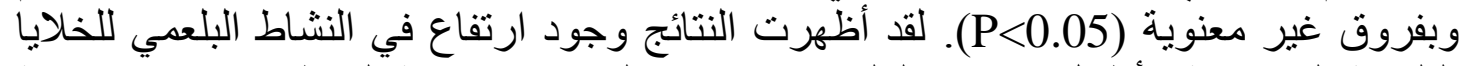

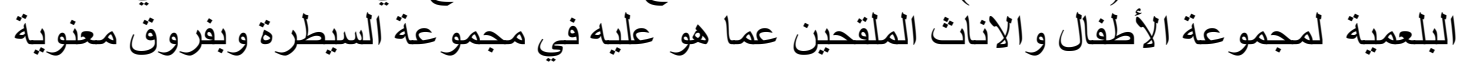

.$(\mathrm{P}<0.05)$

\title{
Immune-Response of Individuals after Immunization with Rubella Vaccine
}

Ghanima Sadik M

Department of Biology - College of Sciences - Baghdad University

Layla Fouad Ali

Accepted on 19/7/2011

Summary

In this study 72 blood samples were collected from healthy individuals. Thirty blood samples were taken from children with age range (12-18) and twenty blood samples from females with age range (12-15) years old 2-4 after two weeks of vaccination with rubella vaccine. Control group included 12 healthy children and 10 healthy females both did not have rubella vaccine through their life. These samples were tested to evaluate the immune-status of individuals after immunization. In this study specific haemagglutination antibodies and $\operatorname{IgM}$ antibodies were measured and total Immunoglobulines (IgM, IgG and $\operatorname{IgA}$ ) also determined. Lymphocyte transformation and ability of phagocyte cell 


\section{المجلة الطبية البيطرية العراقية 35 ( 2 ): 165 - 174 ، 12011.}

to phagocytosis were measured. The results showed decrease in total IgG and $\operatorname{IgA}$ with an increase in the level $\operatorname{IgM}$ in children and females with significant differences $(\mathrm{P}<0.01)$, in comparing with control groups. An increase in the percentage of phagocytic activity of phagocyte cells in both groups (children and females) with a significant differences $(\mathrm{P}<0.05)$ in comparing with control group. Non significant differences in humeral and cellular immune Response between children and female groups.

Keywords: immune, Rubella vaccine, measles, mumps

E-mail: laylafouad1971@yahoocom

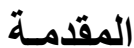

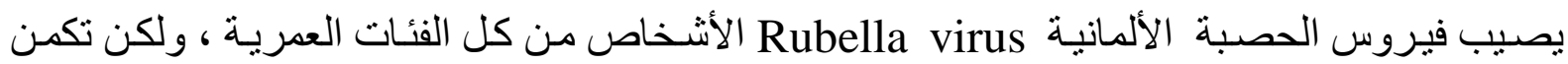

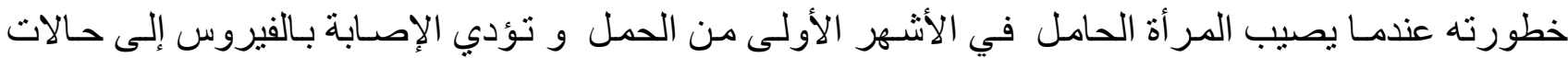

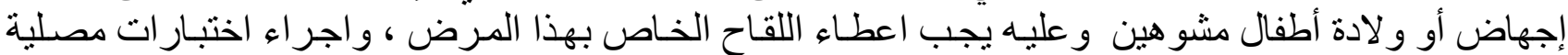

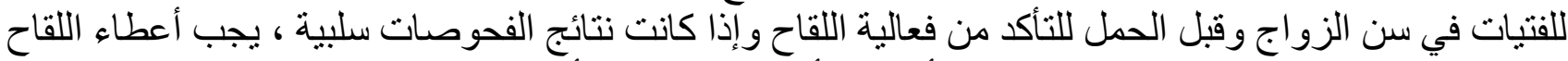

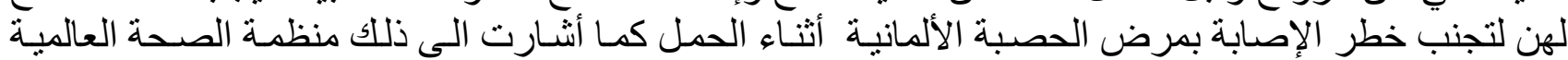

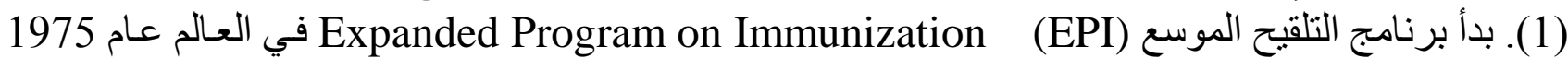

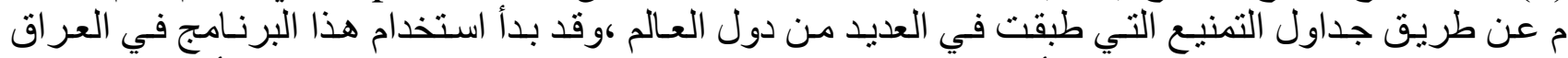

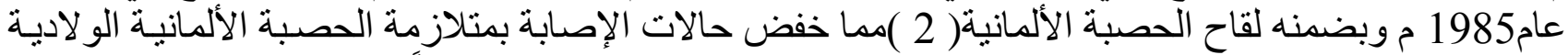

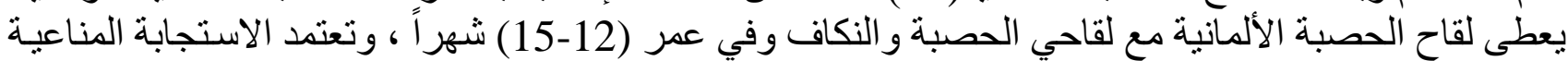

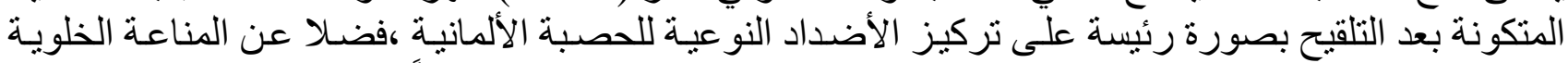

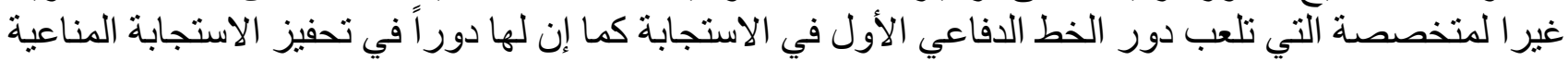

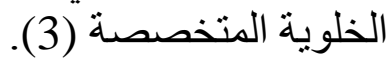
لقاح الحصبة الألمانية صر ح به به عام 1969، ومنذ ذلك الحين تم استعماله بشكل واسع في الكثير من بلدان

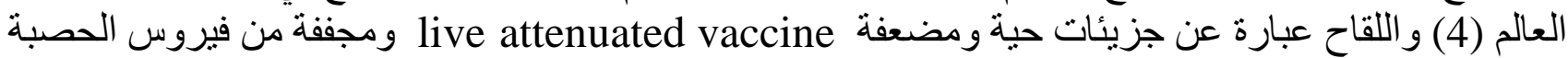

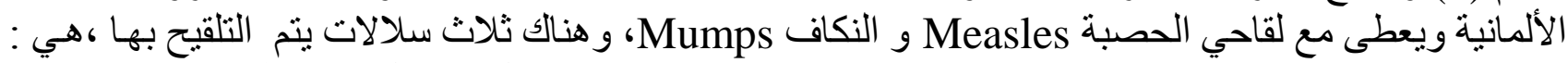

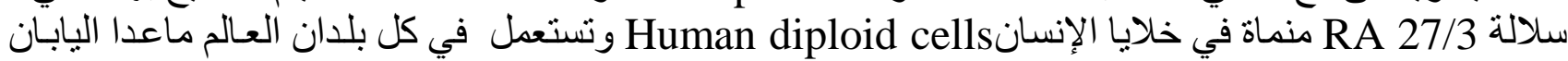

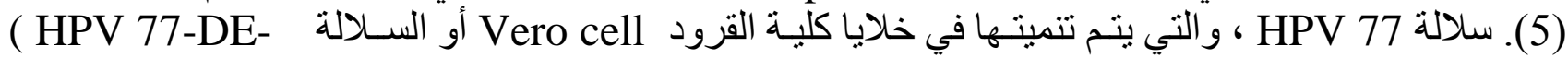

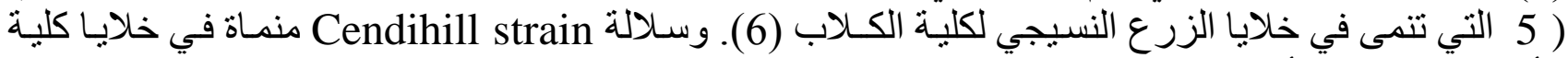

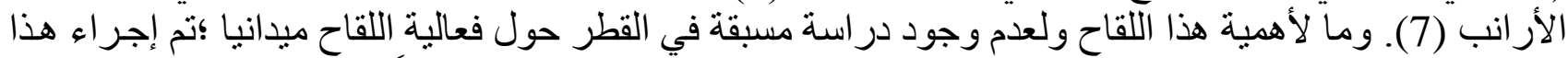

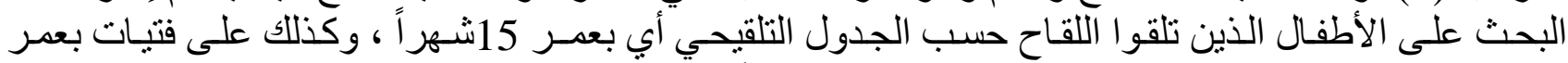

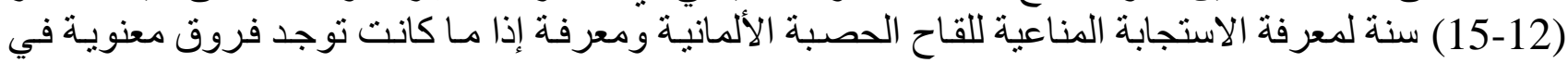
الاستجابة المناعية بين المجمو عتين.

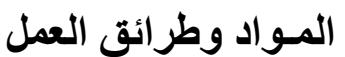

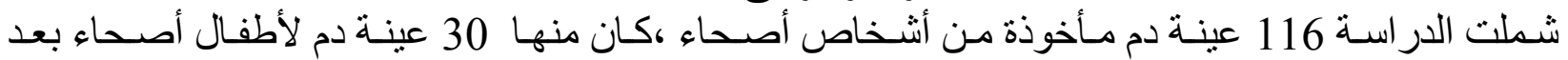

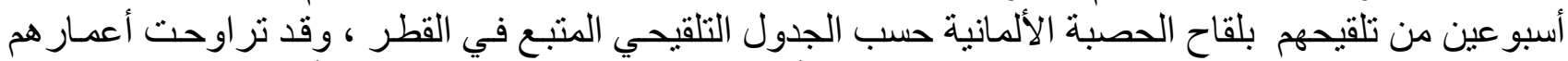

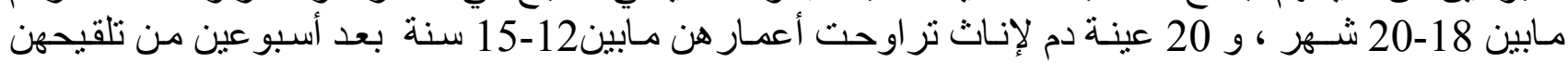

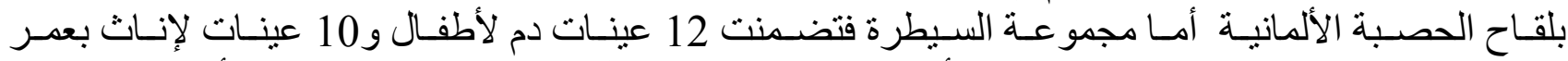

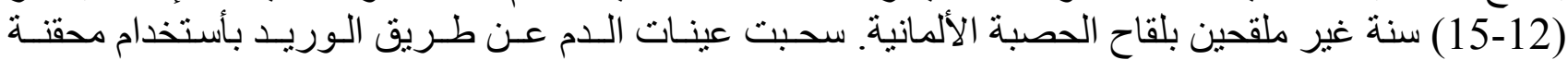

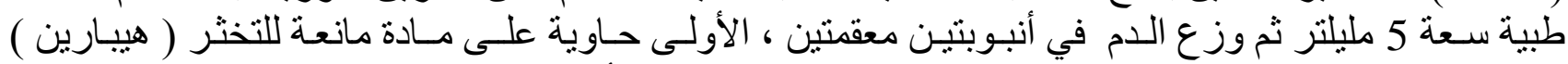

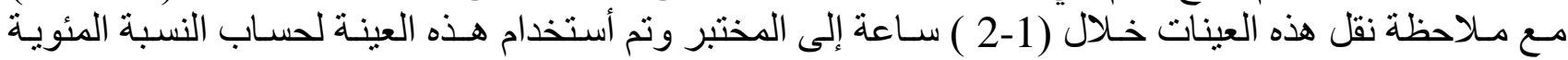

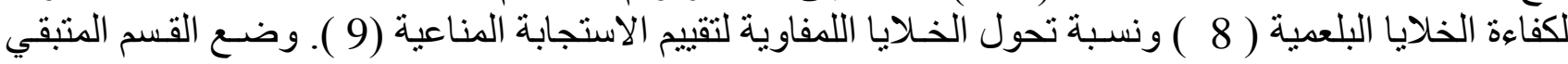




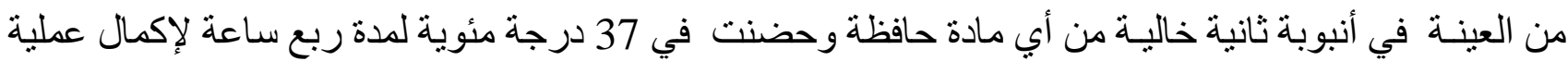

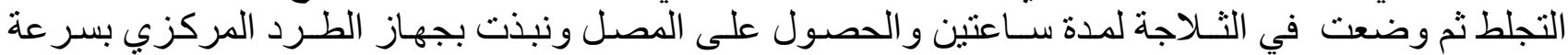

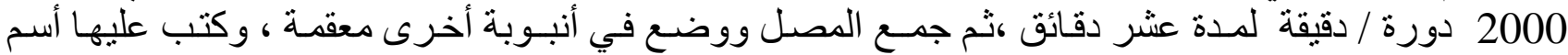

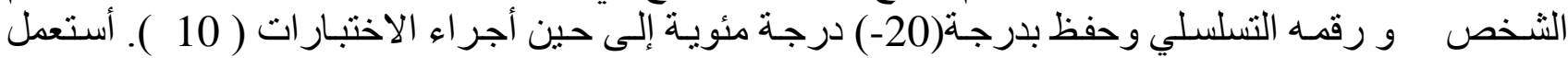

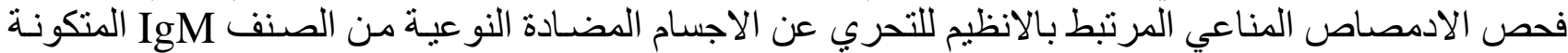

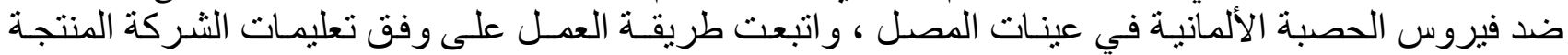

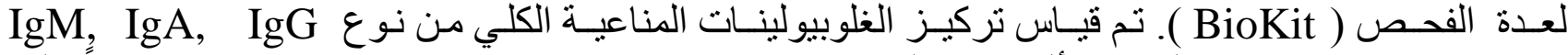

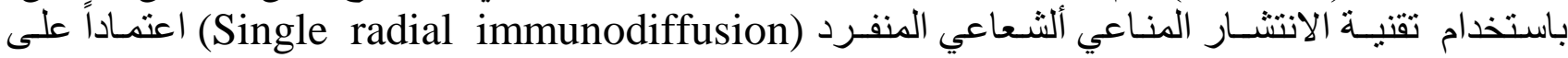

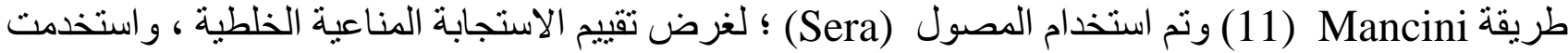

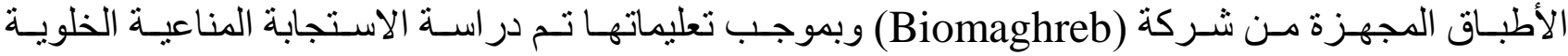

: Cellular immune response

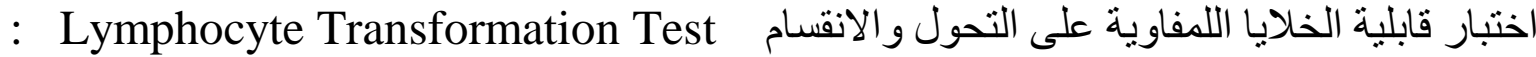

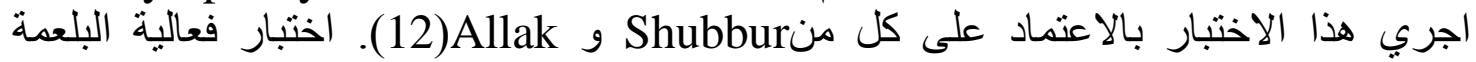

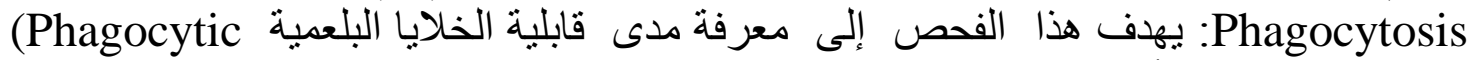

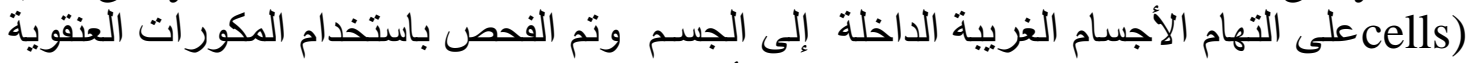

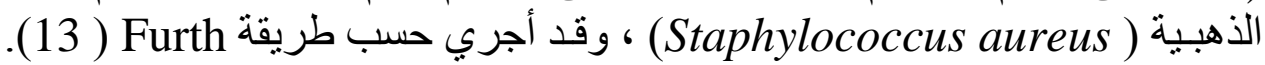

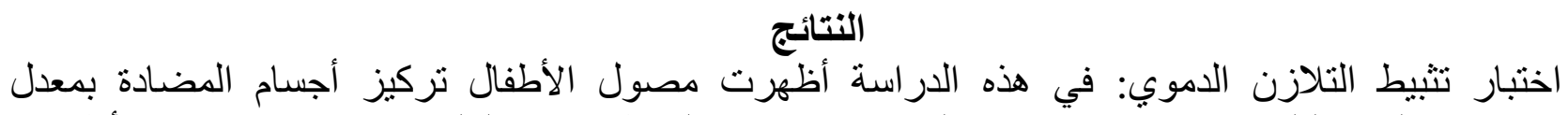

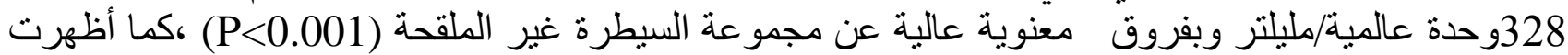

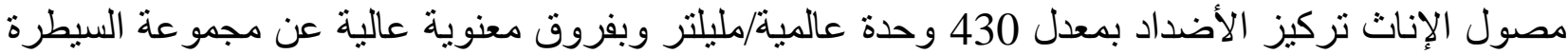

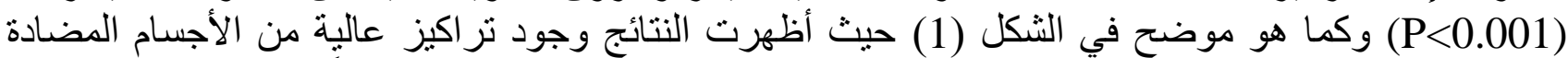

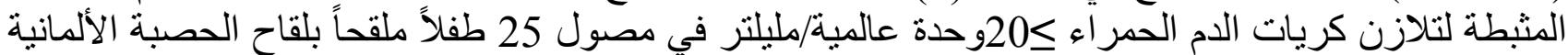

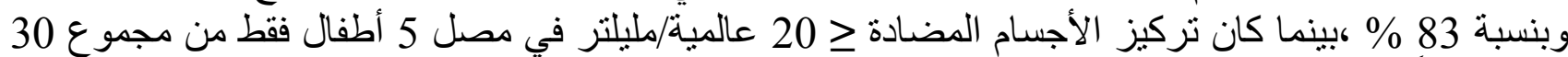

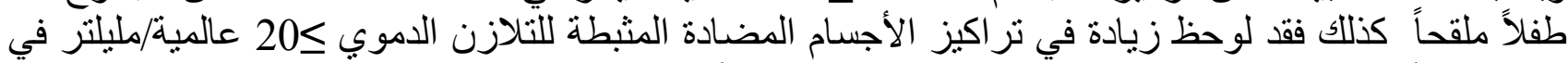

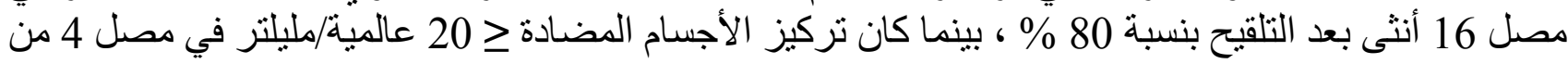

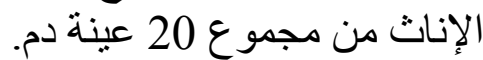

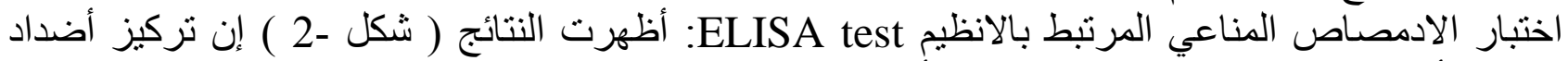

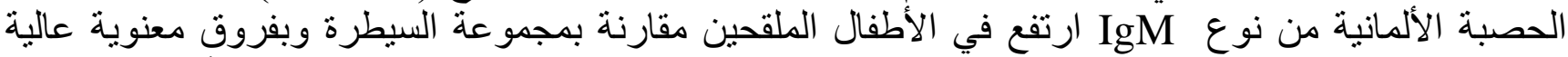

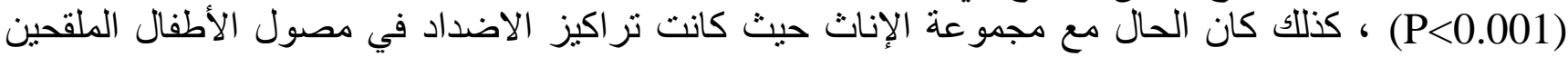

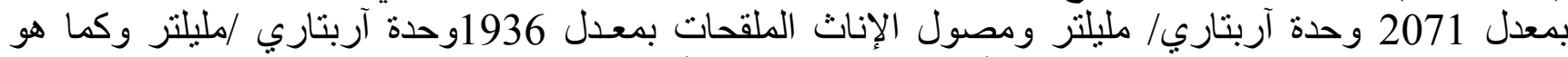

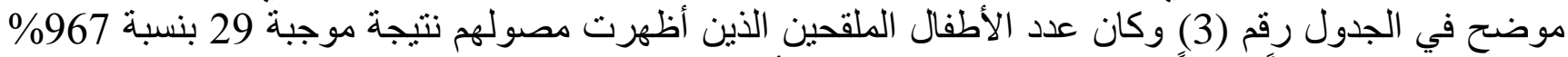

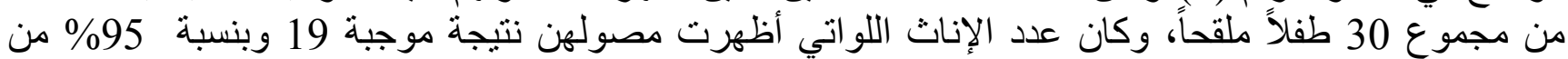
مجموع 20 أنثى ملقحة بلقاح الحصبة الألمانية. 


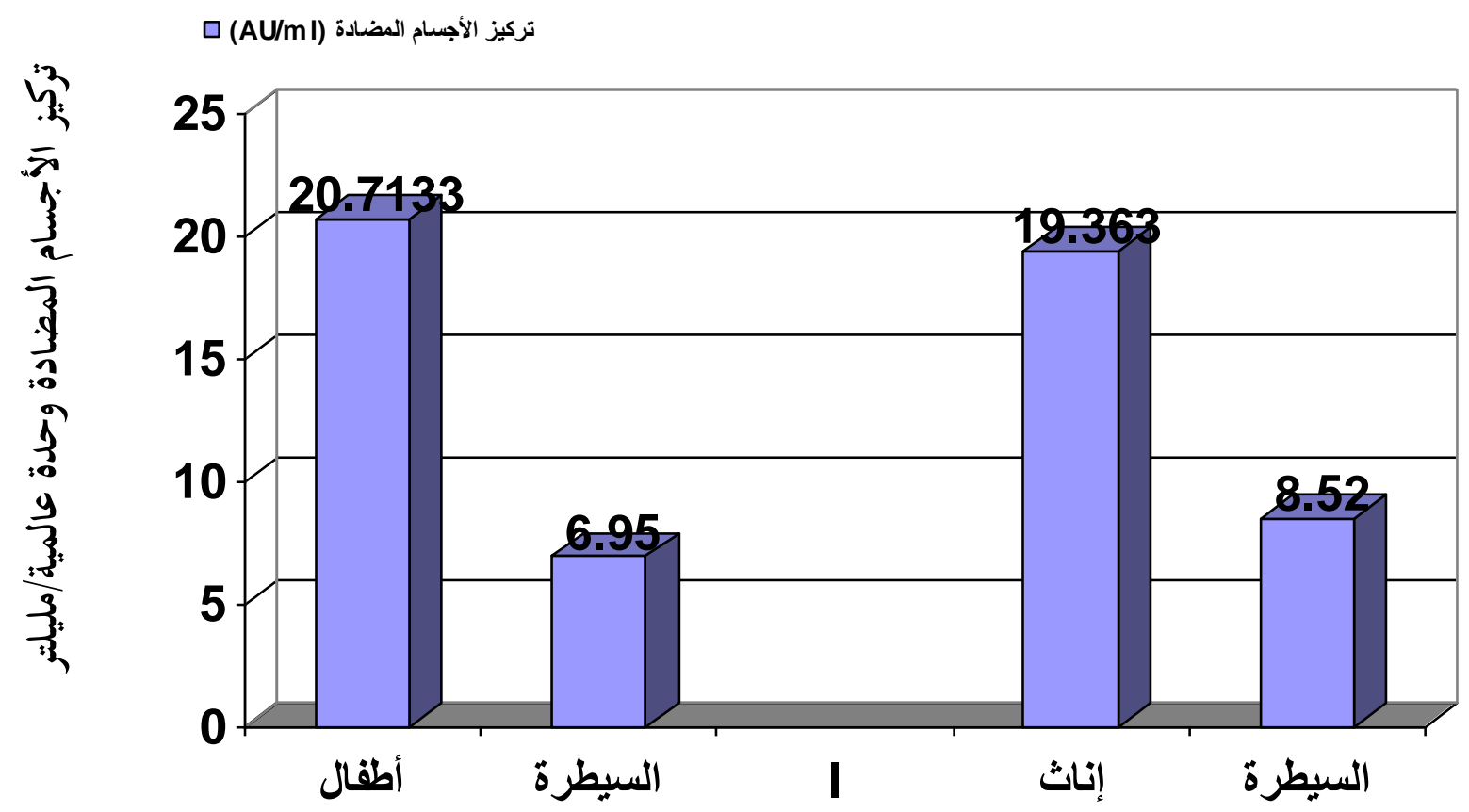

شكل1: معدل تركيز الأجسام المضادة للحصبة الألمانيـة المثبطة لتلازن كريات الدم الحمراء لمجاميع الملقحين والسيطرة مقاسة بالوحدة العالمية|مليلتر لئزئر

تركيز الأجسام المضادة (وحدة عالمية|مليلتر) ه

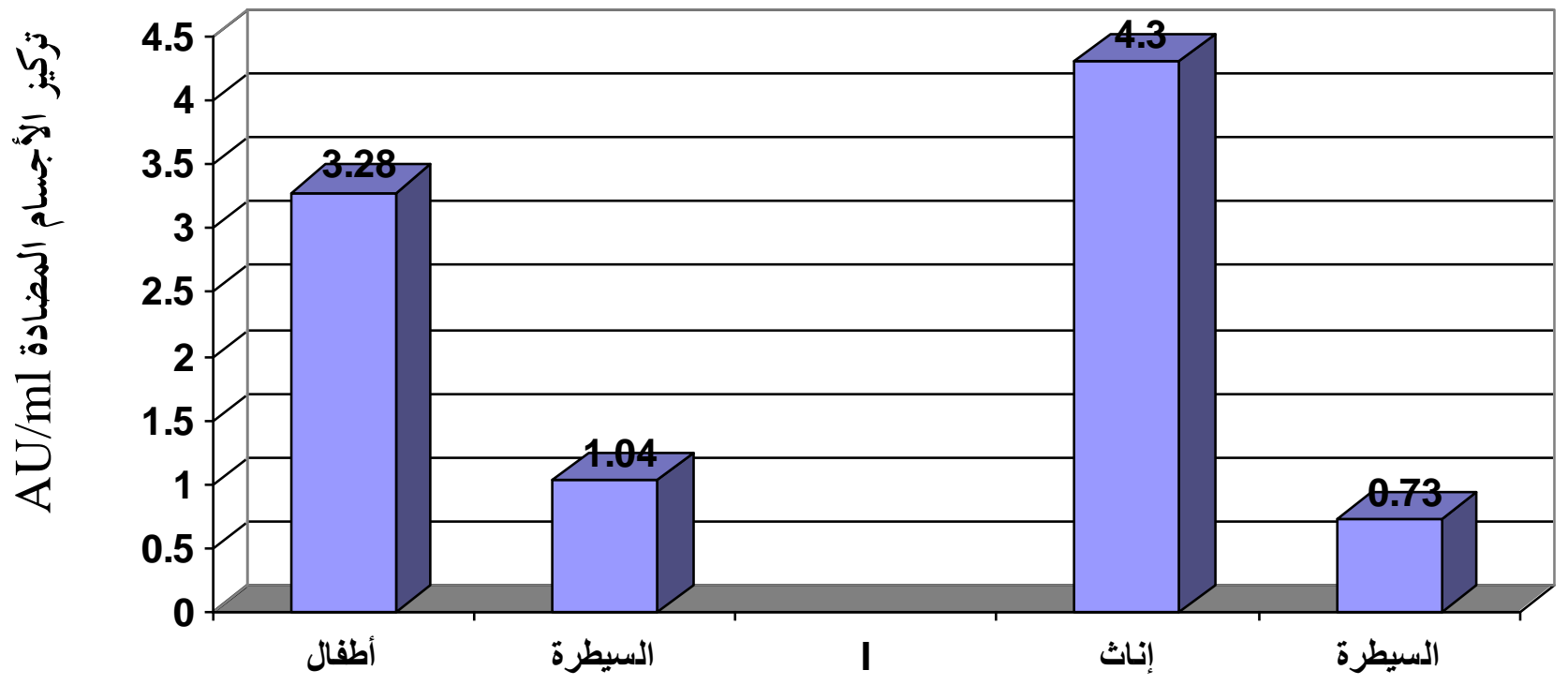

ELISA شكل 2: معدل تركيز الأجسام المضادة IgM للحصبة الألمانية باختبار 
قياس مستوى تركيز الأضداد IgA ، IgM ، IgG الكلي في المصل: إن قياس مستوى تكوين الأضداد IgA ، IgM ،IgG

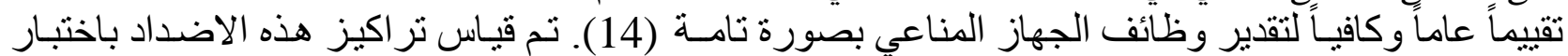

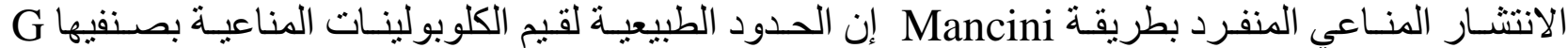

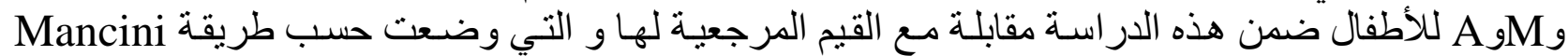

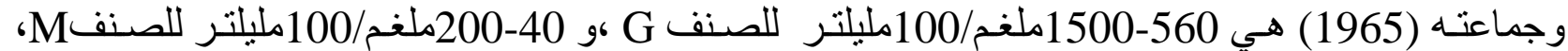

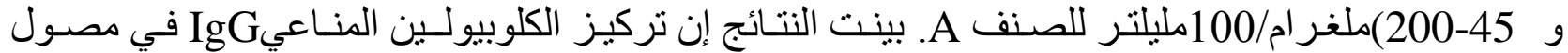

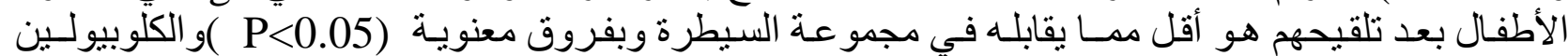

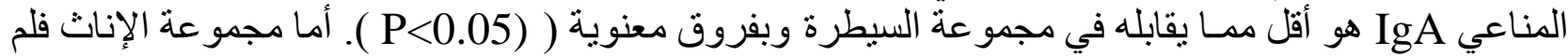

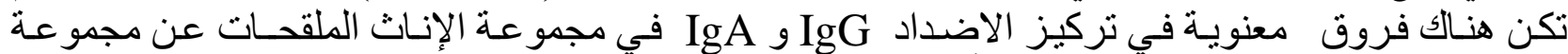

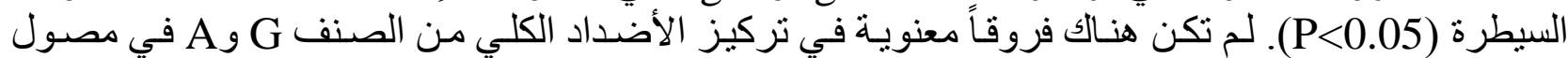

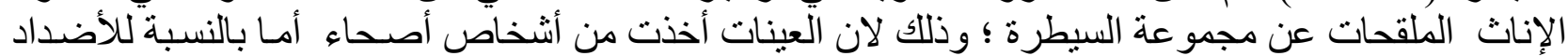

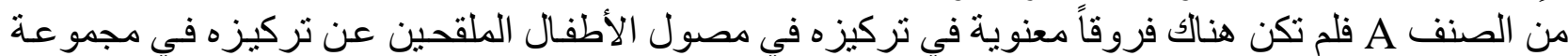
السيطرة.

أما الكلوبيولين المناعي من الصنف IgM فكان هنالك ارتفاعـاً في مستوى تركيزه في مصسول المجاميع

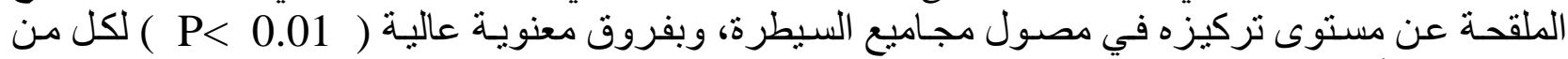

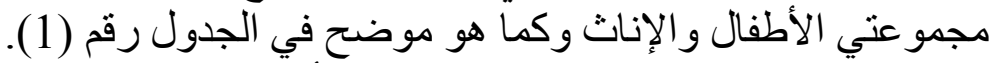

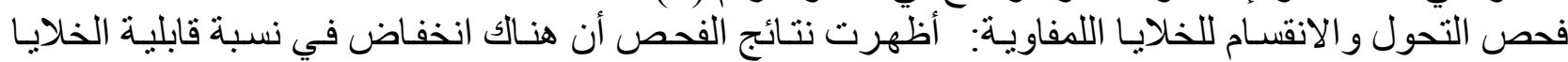

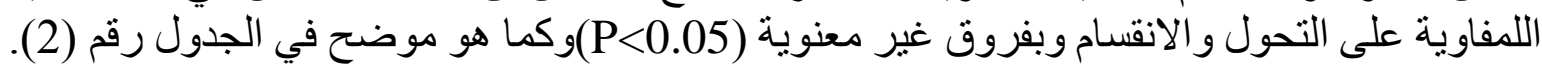

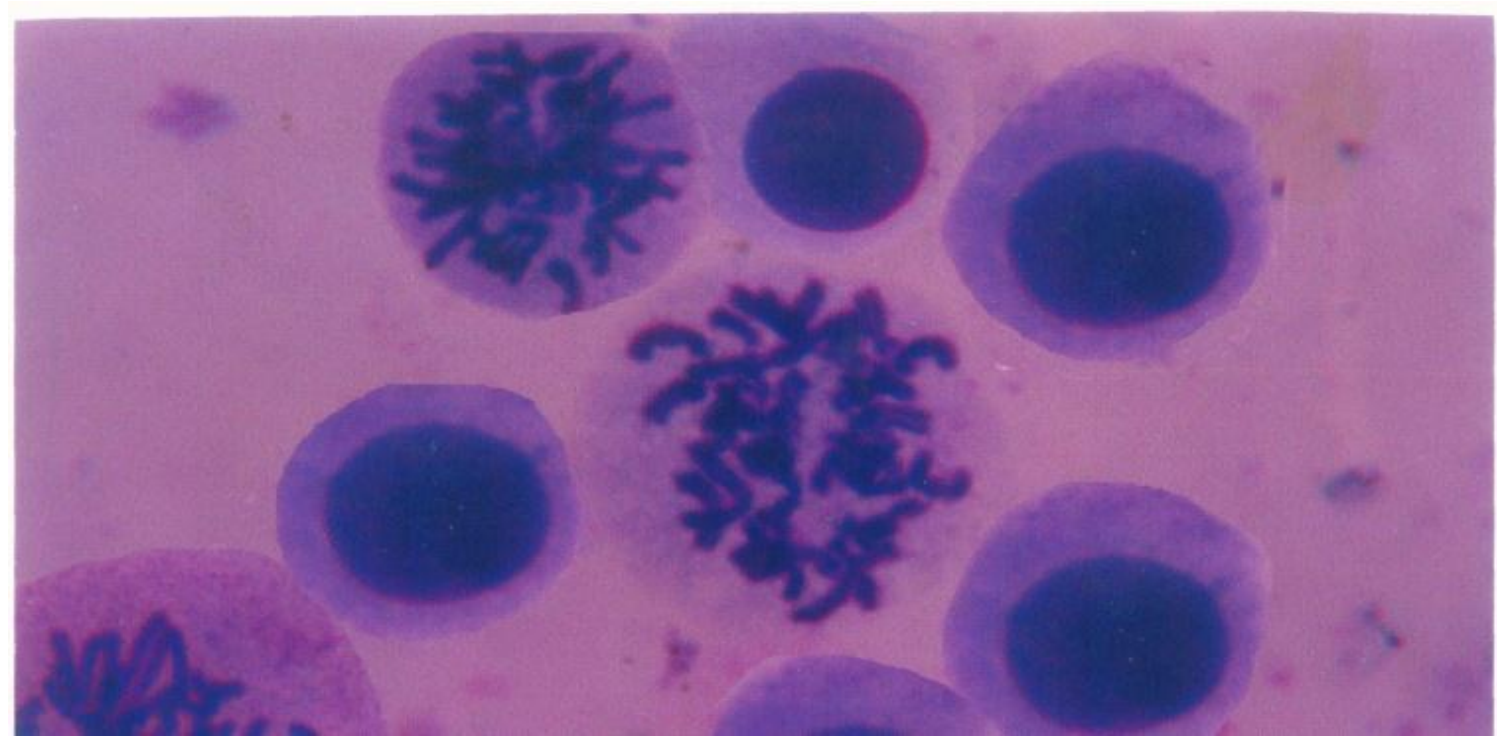

شكل 3 :خلايا لمفاوية متحسة (أرومات لمفاوية (A)(Lymphoblasts) وأخرى غير متحسسة في طور (B) (السكون (Lymphocytes) (النمات ) 
المجلة الطبية البيطرية العراقية 35 ( 2 ): 165 - 174 ، 2011.

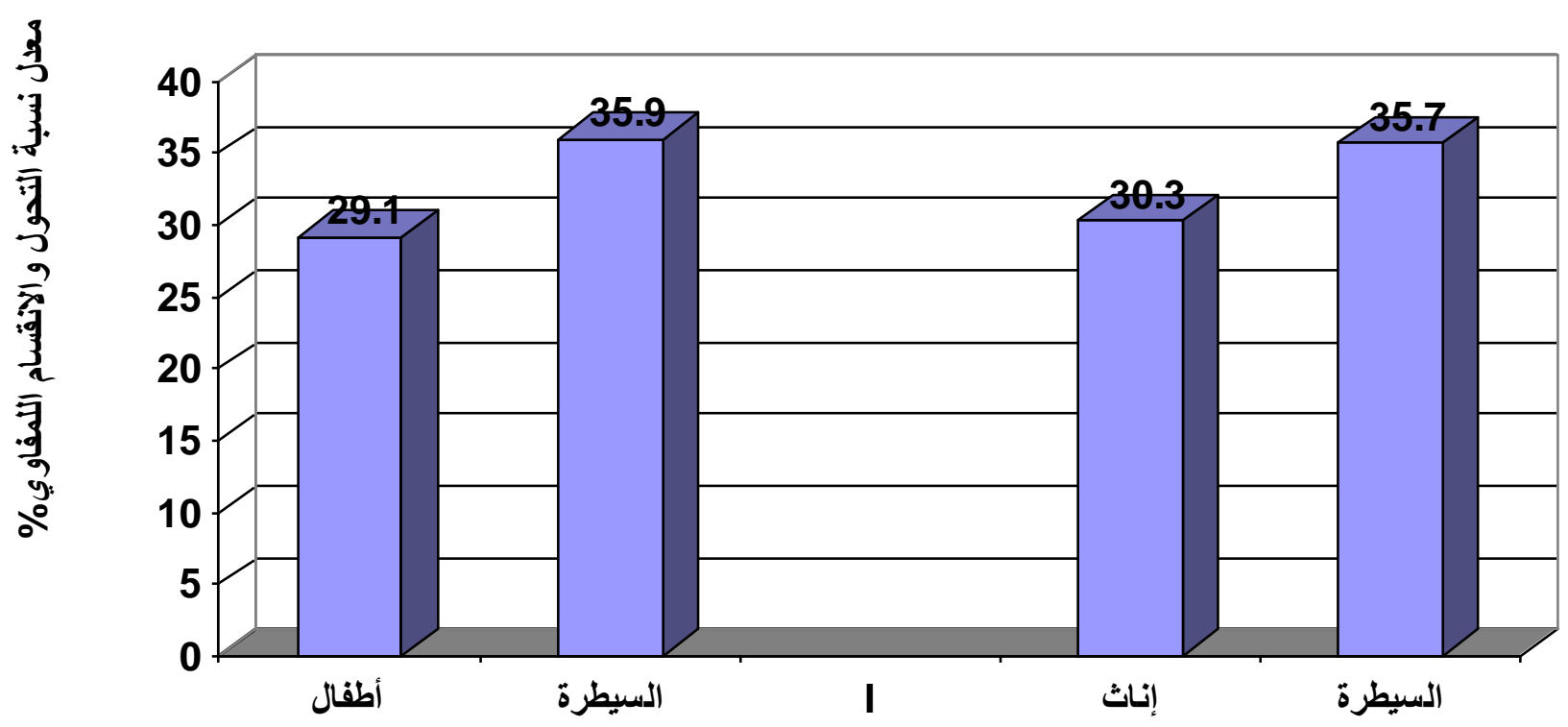

شكل4 : النسب المئوية للخلايا اللمفاوية المتحسة للمشطر (PHA ) في مجموعتي الأطفال والإناث ومجموعتي السيطرة

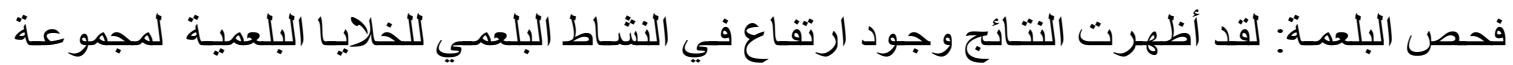

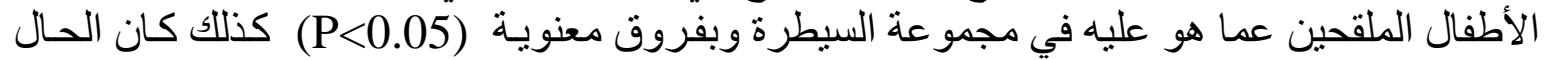

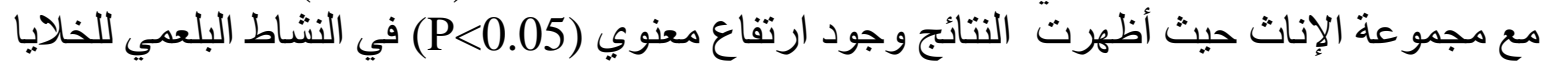

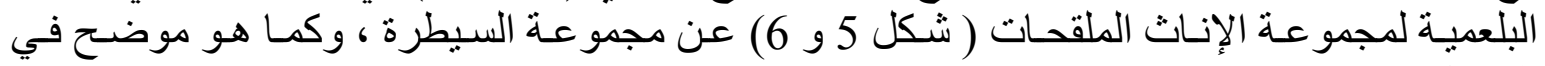

الجدول رقم (3).

شكل 5 :يبين خلايا بلعمية عدلة (Neutrophil) و ملتهمة (400x) Staphylococcus aureus) 
معدل فعالية عمدية البلعمة ه

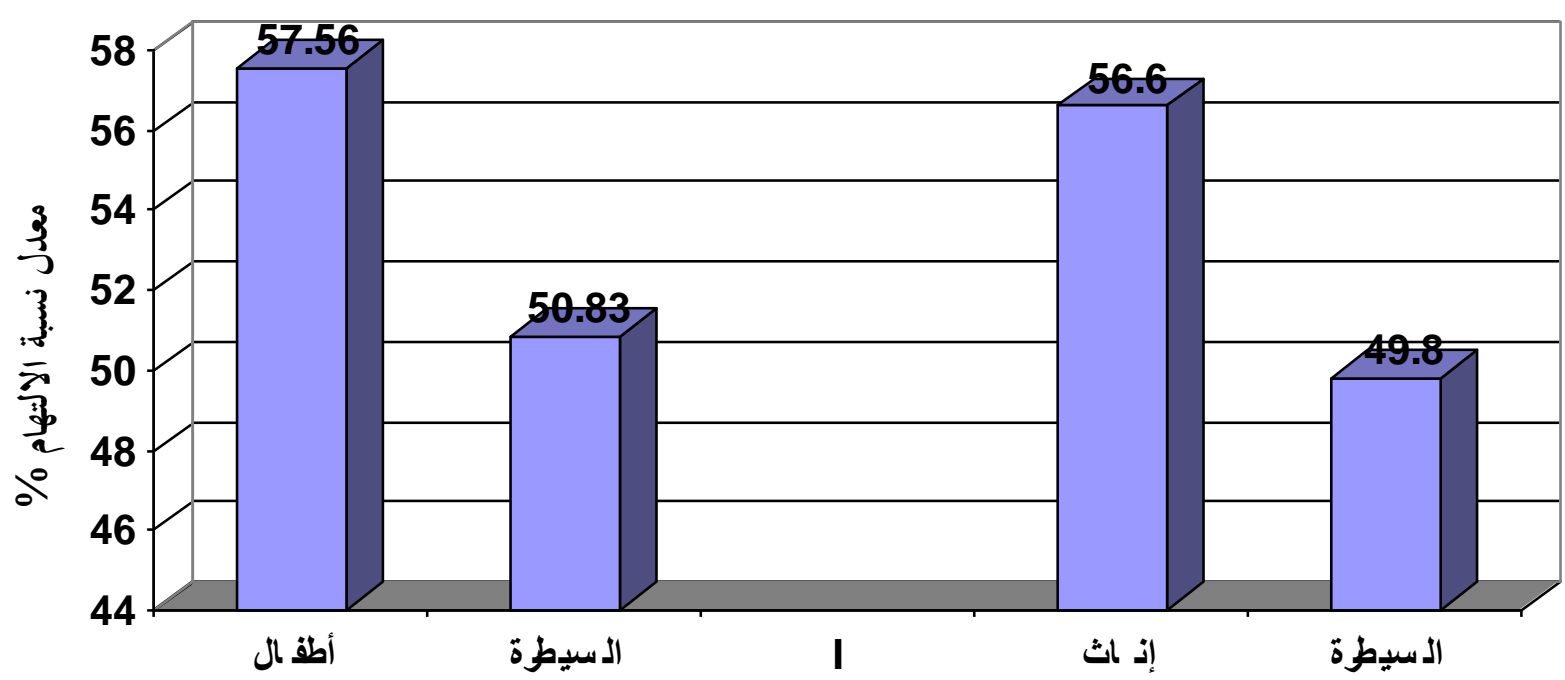

شكل 6: يبين النسب المئوية لقابلية الخلايا البلعمية على التهام بكتريا Staphylococcus aureus في مجموعتي الأطفال والإناث ومجموعتي السيطرة

\section{المناقشة}

أظهرت هذه الدر اسة إن لقاح الحصبة الألمانية والذي يعطى مع لقاحي الحصبة و النكاف فعال جدا

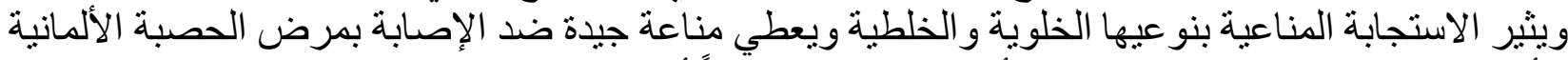

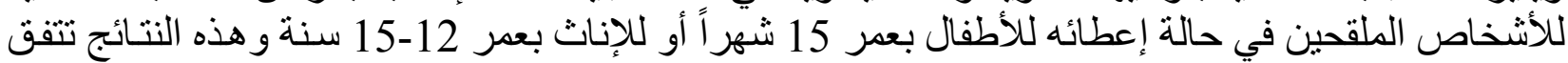

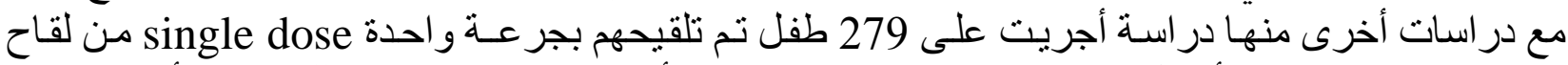
،كانت نسبة الأطفال الذين تكونت لديهم تر اكيز من الأجسام المضادة النو عية للحصبة الألمانية كافية

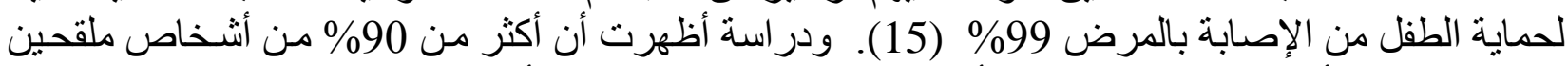

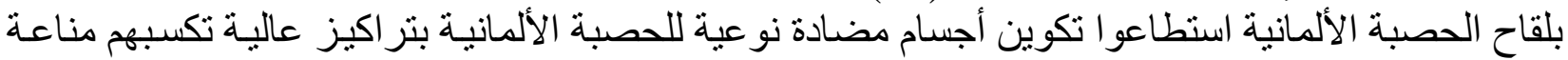

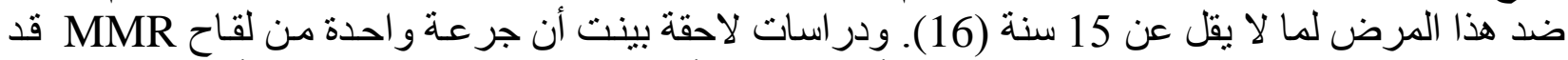

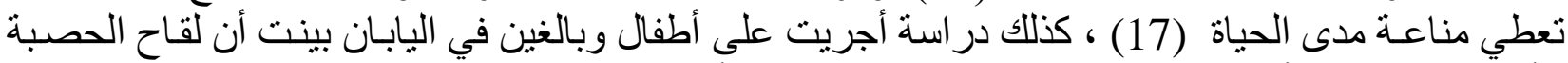

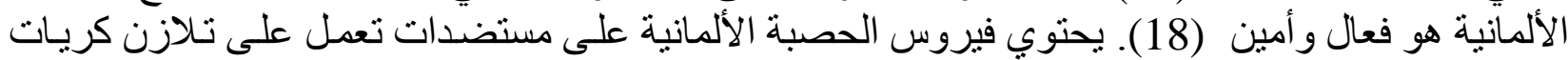

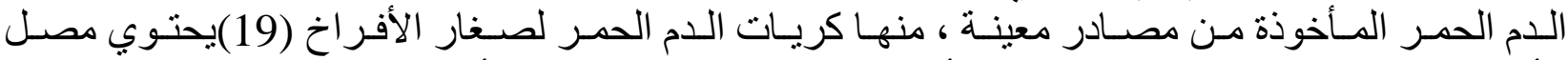

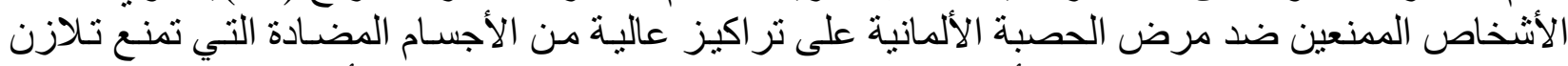

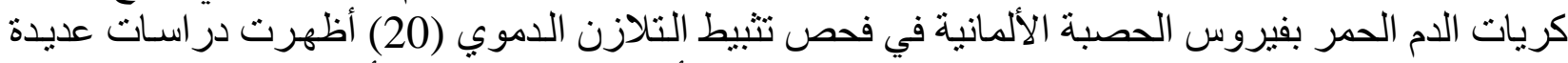

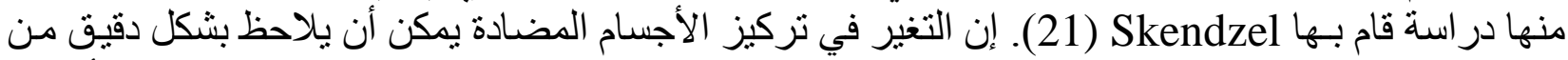

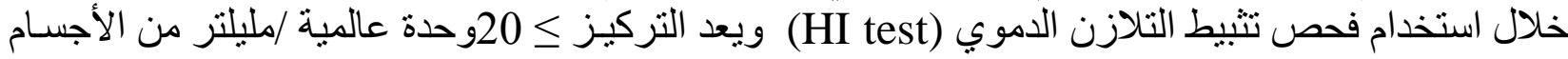

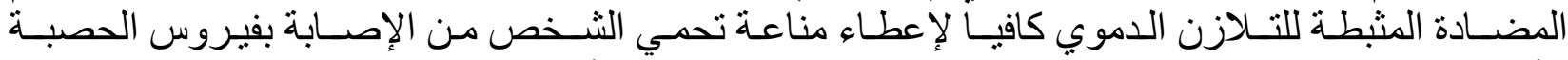

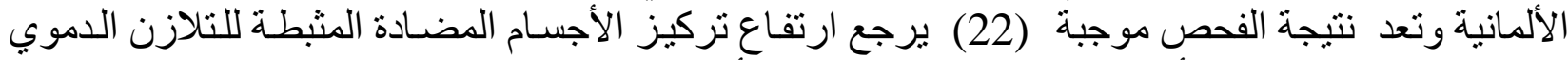

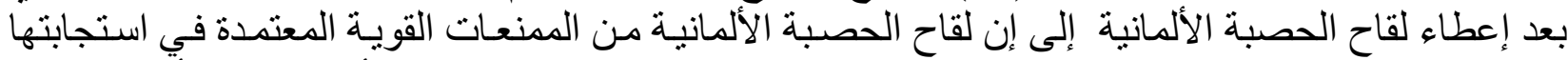

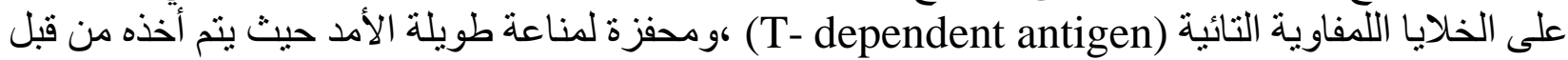

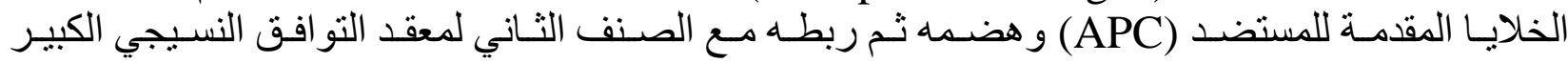

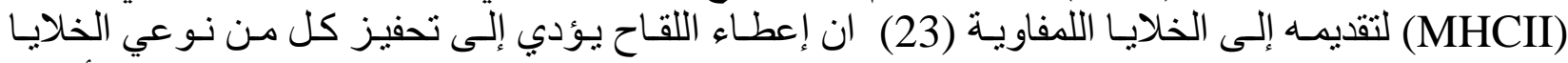

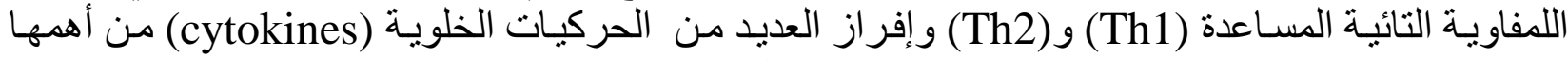

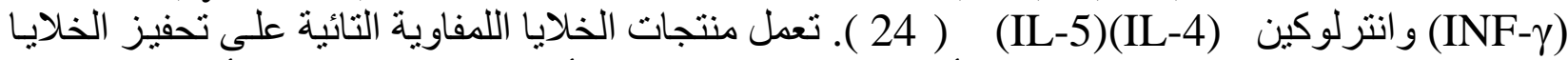

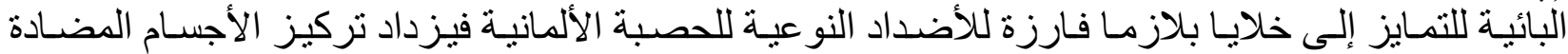
المثبطة للتنازن الدموي (25) و هذا يتو افق مع نتائج هذه الدر اسة والتي تتفق مـع (26) وتثنير إلى إن تركيز 


\section{المجلة الطبية البيطرية العراقية 35 ( 2 ): 165 - 174 ، 2011.}

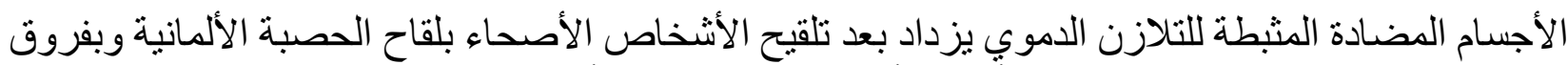

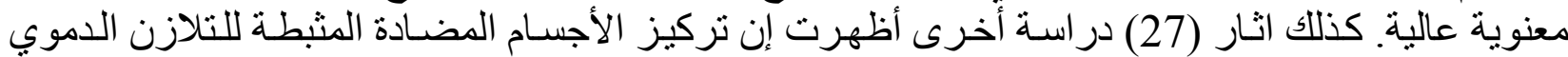
يزداد بعد إعطاء اللقاح إلى الأشخاص غير الملقحين وغير المصابين بالحصبة الألمانية في عمر 12 سنة. كما

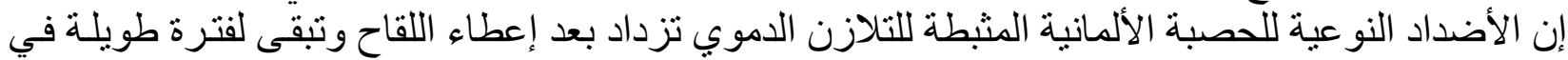

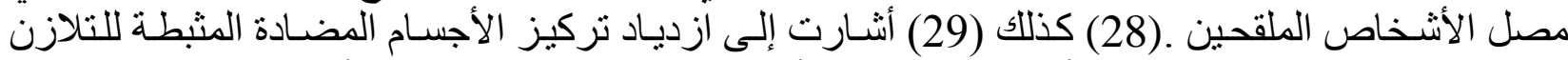
الاموي بعد إعطاء لقاح الحصبة الألمانية و إن بقاء الأضداد في مصول 79 \% من الأس الأشخاص الملقحين تبقى

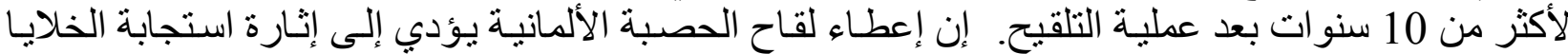

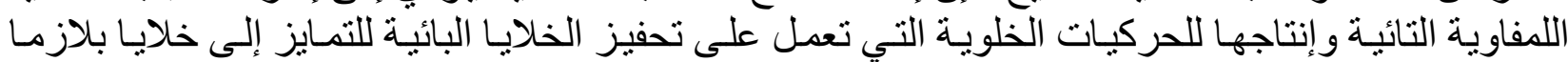

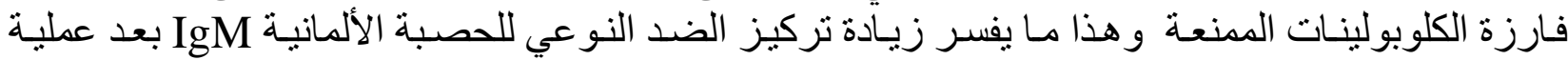

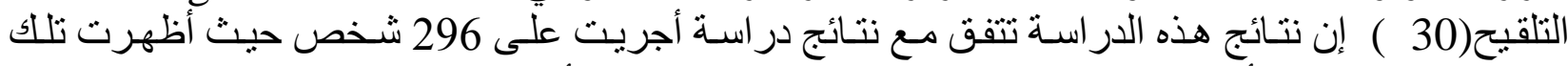

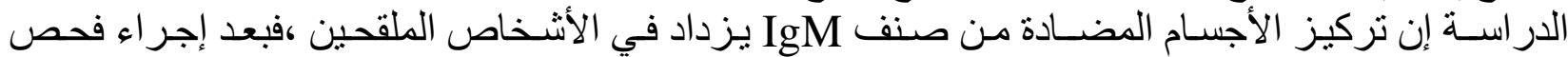

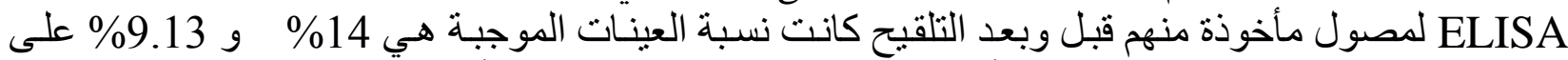

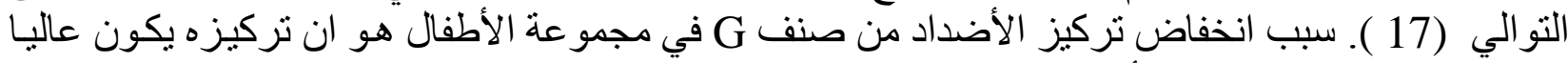

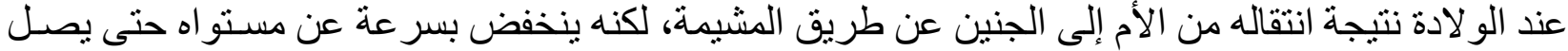

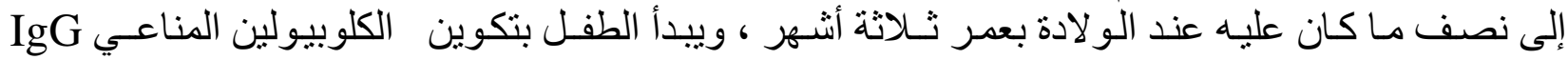

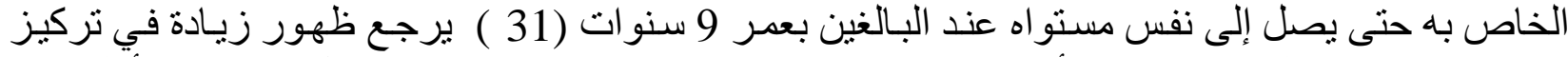

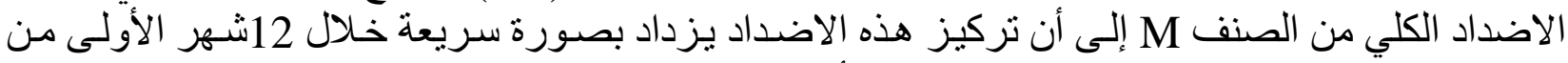

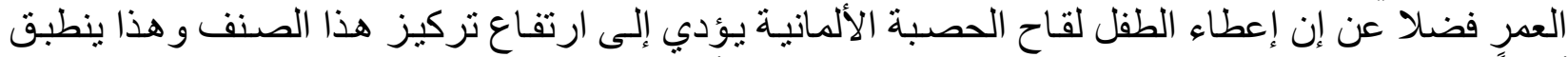

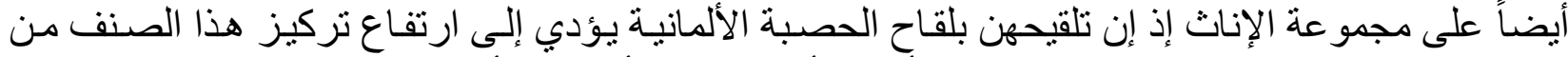

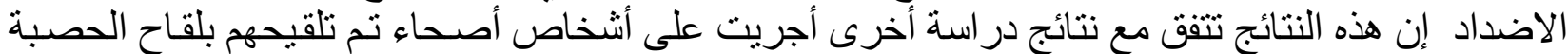

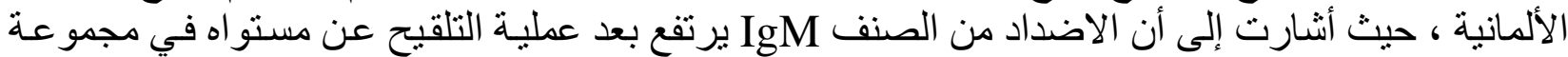

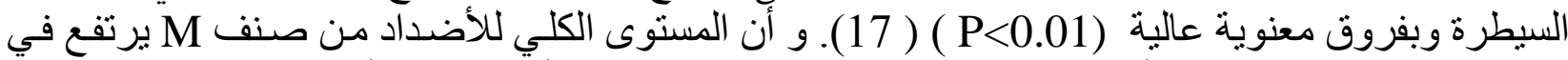

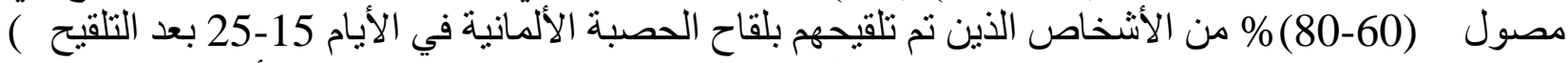
(Leif et al2001)

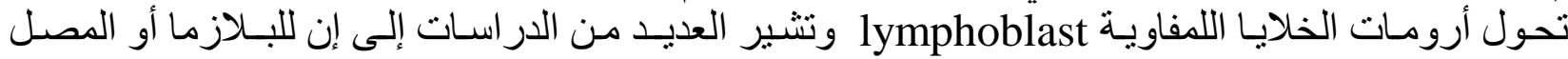

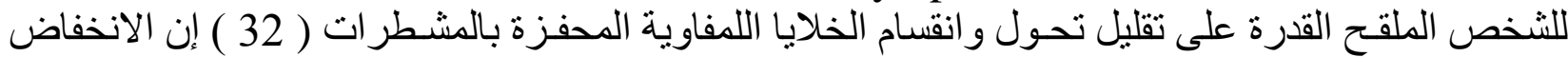

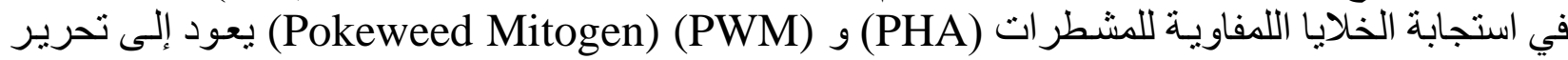

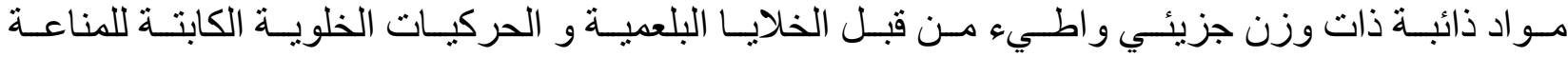
(Immuno-suppresive cytokines)

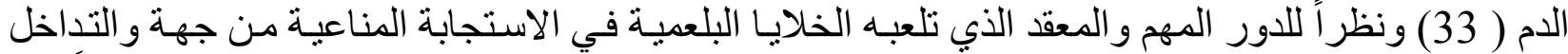

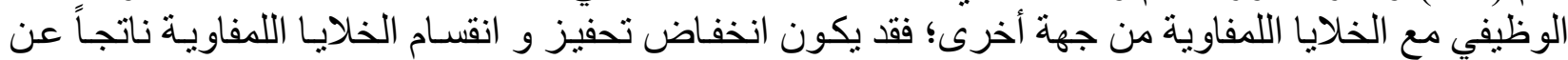

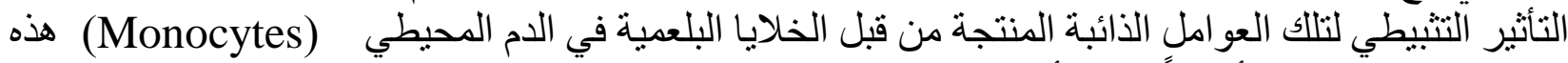

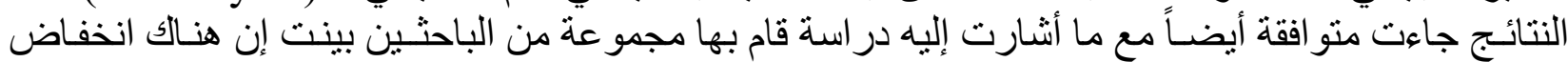

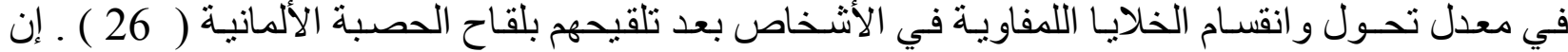

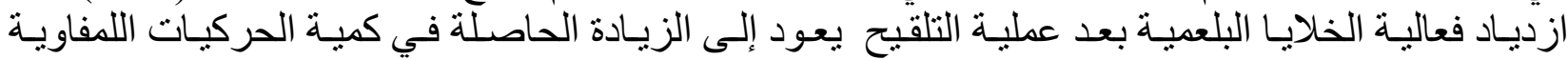
(lymphokines)

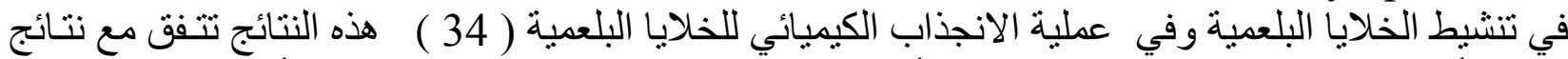

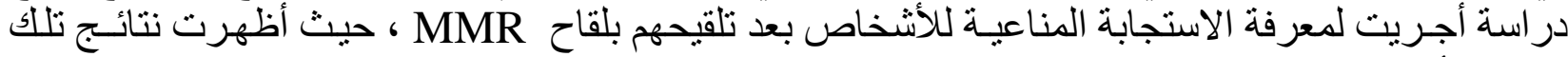

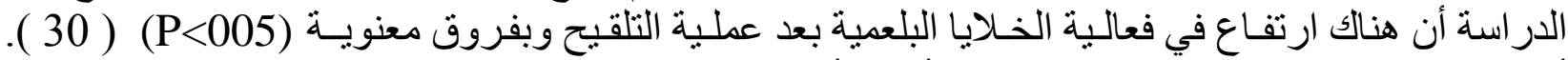

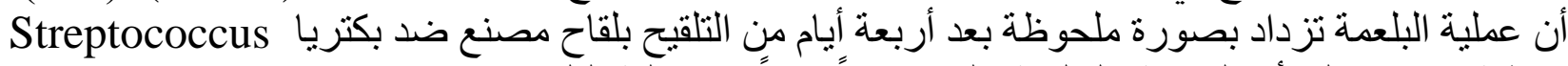
معطية مؤشر ا على أن المناعة الخلوية تلعب دور أ مهماً في عملية التلقيح. 


\begin{tabular}{|c|c|c|c|}
\hline الفروق المعنوية & الاتحراف المعياري & النسبة المئوية لفعالية & المجموعة \\
\hline \multirow{2}{*}{$P<005$} & 884 & 5756 & أطفال \\
\hline & 976 & 5083 & السيطرة \\
\hline \multirow{2}{*}{$P<005$} & 549 & 566 & إناث \\
\hline & 705 & 498 & السيطرة \\
\hline
\end{tabular}

\section{جدول (2): تراكيز الكلوبيولين المناعي IgAو وIgM الكلي في مجموعتي الأطفال والإناث الملقحين ومجاميع السيطرة

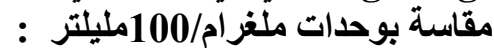

\begin{tabular}{|c|c|c|c|}
\hline التركيز/IgA & التركيز/IgM & التركيز/IgG & المجموعة \\
\hline 10878 & 106993 & 70922 & أطفال \\
\hline 13927 & 94433 & 84663 & سيطرة \\
\hline 16862 & 231535 & 18721 & إناث \\
\hline 11135 & 11183 & 10025 & سيطرة \\
\hline
\end{tabular}

\begin{tabular}{|c|c|c|c|}
\hline الفروق المعنوية & الانحراف المعياري & والانقسام اللمفاوية للتحول & المجموعة \\
\hline \multirow{2}{*}{ NS } & 137 & 291 & أطفال \\
\hline & 12 & 359 & السيطرة \\
\hline \multirow{2}{*}{ NS } & 218 & 303 & إناث \\
\hline & 16 & 357 & السيطرة \\
\hline
\end{tabular}

\section{References}

1. WHO (2005) . Measles mumps and rubella vaccine. WHO / EPI Rev 1 .

2. WHO /EPI (1995).Global program for vaccines and Immunization Expanded program on immunization Immunization policy .WHO/EPI/GEN/95 03 / Rev 1.

3. EPI - WHO Europe(1994) .Measles: a strategic framework for the elimination of measles in the European region .Copenhague Intervirology. Vol 41 No 4-5.

4. CDC (2002). Shortage of varicella and measles mumps and rubella vaccine .MMWR .51:190-197.

5. American Academy of Pediatrics (1994). Rubella In Peter G edred book Reported of the committee infectious disease 23rd edEIK groove Vllaje IIIAAP :406-412.

6. CDC (1994). General recommendations of the (ACIP) on immunization. MMWR 43 NoRR-1:1-20.

7. EPI (1996). Immunization in English speaking Caribaen . Weekly epidemiology record 71:217-223.

8. Juhela S Hyoty H Meriste S and Lonnrot M (1999). Comparison of enterovirus specific cellular immunity in two populations of young children vaccinated of live poliovirus vaccine .Clin Exp Immunol. 117(1):100-105 .

9. Boschwitz JS Batanghari JW Kedem H and Relman DA (1997). Bordetella pertussis infection in human monocytes inhibits antigen dependent CD4 T-cell proliferation. J Inf Dis; 176:678-686.

10. Reichler M Adnan A Soad K Azmi M James P Samir F Haidar O Rafi A and Harry F (1997). Outbreak of paralytic Poliomyelitis in a highly immunized population in Jorden JInf Dis 175 (supply):S62-70.

11. Mancini G Garbonara AO Herman Furth R Theda L and Leijilt P (1985). In vitro determination phagocytosis and intracellular killing by poly morphonuclear and mononuclear phagocytosis In:Hand book of Experimental Immunology. ( $3^{\text {rd }}$ ed) Blackwell Scientific Publication .Vol 2 P: 1-14

12. Shubber EK and Allak BMA (1985). Spontaneous chromosomal aberrations in human lymphocytes I Effect of culture conditions. The Nucleus. 29 (3): 92-98. 
13. Furth (1965). Immunochemical quantitation of antigen by single radial immune diffusion Immunochemistry. 2:235-254.

14. Muccusker C Somervill W Gray V and Mazer B (1997). Specific antibody response to dipheria and tetanus revaccination in children evaluated for immuno-deficiency. Ann Asth Immun .79:145150 .

15. Harris C (1997). Childhood vaccinations health and human services education and related agencies april 16 .

16. ACIP (2002). Recommendation for avoiding pregnancy after receiving a rubella-containing vaccine December 14. 50(48):11-16.

17. Wondatir A Nigatu DJ Nokes BJ Cohen DW and Brown AJ (2003). Pre and post vaccine measles antibody stats in infants using serum and oral fluid testing: an evaluation of routine immunization in Addis Ababa. Ethiopia Med Lab Evaluation Immun.MLE-B2.

18. Takeuchi Y Togashi T Sunakawa K Katou T and Hitoshi N (2002). Fields trial of combined measles and rubella live attenuated vaccine Kansenshgaku-Zasshi Jan; 76 (1): 56-62.

19. Koneman EW Allens SD Dowell VR Janda WM Sommers HM and Winn WC (1988). Atlas and Textbook of Diagnostic Microbiology $3^{\text {rd }}$ ed Chapter 16 Diagnostis of infections caused by obligate intracellular pathogens : Virus Chlamydia and Ricketsha JB Lippincott Co Pp:752-753.

20. WHO (1997). Estimated deaths occurring and prevented by immunization for selected diseases Rev3.

21. Skendzel LP Wilcox KR and Endrson DC (1983). Evaluation of assay for the detection of antibodies to rubella Am J Clin Path 80: 594-598.

22. Laura Z and Susan R (2002). Rubella VPD Surveillance Manual $3^{\text {rd }}$ edition Chapter 11 Rubella :111.

23. Cooper P Espinel I Paredes W Guderion R and Nutman T (1998). Impaired tetanus specific cellular and humeral responses following tetanus vaccination in human onchocerciasis J Inf Dis; 178:11331138.

24. Barrios C Brawand P Brand C Lambert Pand Siegirt C(1996) Neonatal and early life immune response to various forms of vaccine antigens qualitively differ from adult response.EurIImmunology :26:1489-1496.

25. Wibel R (1980). Clinical and laboratory studies of live attenuated RA 27/3 and HPV 77-DE rubella virus vaccine (40931)Proceeding of the Society for Experimental Biology and Medicine. 165:44-49.

26. Elena B Paul B Philip Rand Cooper L Z (1979). Impaired cell-mediated immune response in patients with congenital rubella: Correlation with gestat- ional age at time of infection Pediatrics. Vol 64 No 5 :620-626.

27. Leif G Erik B and Margareta B(2001).Immunogenicity and reactogenicity of an a new measles mumps and rubella vaccine when admistrated as a second dose at 12 Yof age Scandinavian .J Infect Dis.Vol 33 No 7 (1) : 545-549.

28. Stecee RS Talley MS Skeels MRand Lanier GA (1985). Coprasion of enzyme-linked immunosorbent assay haemagglutination inhibition and passive latex agglutination for determination of rubella immune status. J Clin Microbiol. 21:140-142.

29. Herman KL (1985). Rubella virus in diagnostic procedure for viral Reckettsial and Chlamydial infection. JAMA. 1(2):725-758.

30. Patricia C Grustadauria C and cuffini M (1997). Presence of neutralizing domain in an isolate of rubella virus in Cordoba Argentina Clin Diagn Lab Immuno .14:493-495.

31. Abida I Shamin R and Bokhari A(1997). Occurrence of rubella Antibody IgG in general population .Medical J Mar. 35(1): $17-22$.

32. Revers T Szigeti Mand Schuler D (1974). The role of the serum factors in the lymphocyte transformation test of children acute leukemia. Act Padiater Scand. 63: 517.

33. Yang KD and Hill HR (1991). Neutrophil function disorder. J Pediatrics ; 119:343-354

34. Liu X and Long R(1990). [Studies on immunoregulation and hypersensitivity of secretory otitis media] Hua Hsi IKo TaHsueh Pao. 21(4): 424-6 (Abst). 